\title{
Sobre o fluxo informacional em tempos de Internet: estudo dos contextos comunicacionais
}

\author{
GUILHERME HAAS - guilhs@hotmail.com \\ Universidade Tuiuti do Paraná \\ Mestre em Comunicação e Linguagens pela Universidade Tuiuti do Paraná
}

\begin{abstract}
Resumo
O artigo analisa o impacto da Internet como meio de produção e veiculação de conteúdos que transformam as esferas públicas e privadas das redes de comunicação. O estudo propõe um resgate de teorias sócio-culturais que investigam as transformações dos processos comunicacionais. $\mathrm{O}$ artigo aborda os aspectos político-econômicos da comunicação sobre a ótica da liberdade de imprensa e da legitimação dos veículos midiáticos na cultura digital. O texto agencia autores do comunicacional, da cibercultura, da sociologia e da filosofia como Terry Eagleton, Armand Mattelart, Wilson Gomes, Mauro Wolf e André Lemos.
\end{abstract}

\section{Palavras-chave}

Comunicação, internet, liberdade de imprensa.

\begin{abstract}
The paper analyzes the impact of the Internet as a media of production and distribution that modifies the public and the private spheres of the communicational field. The article recovers theories from the socio-cultural studies that investigate the transformation of the communication processes. The article focuses on the political-economic perspectives of press and journalism and the legitimacy of the media in the digital culture. The authors are from the communication, cyberculture, sociology and philosophy area such as Terry Eagleton, Armand Mattelart, Wilson Gomes, Mauro Wolf and André Lemos.
\end{abstract}

Keywords

Comunication, internet, free press.

Artigo recebido em 21/04/2010

Aprovado em 20/09/2011 


\footnotetext{
As ferramentas pressupõem sempre uma máquina, e a máquina é sempre social antes de ser técnica. Há sempre uma máquina social que seleciona ou assimila os elementos técnicos empregados (DELEUZE; PARNET, 1998, p. 84).
}

A consolidação da Internet como potencial meio de informação da sociedade exige um questionamento sobre as práticas dos conglomerados de mídias no ambiente de rede. Afinal, quais são os impactos da mudança tecnológica para os processos comunicacionais? Há a transposição do modelo político-econômico dos meios de comunicação para o ambiente da Internet; ou seja, como se organiza os pólos de produção e veiculação de informações e conteúdos na chamada cultura das mídias?

De início, a pesquisa recupera conceitos gerais da comunicação que auxiliam a investigação sobre as mudanças gerenciadas pela cultura digital - especialmente a Internet - aos meios de informação e entretenimento. A proliferação de conteúdos na rede implica uma discussão sobre a liberdade de expressão e a legitimidade das fontes; debates que se inter-relacionam e se suplementam. Da esfera social ao pessoal, a pesquisa esboça uma abordagem sobre o impacto das novas tecnologias no âmbito individual, que definem escolhas, modificam afetos e induzem o consumo pela interface da tela do computador.

\section{Comunicação: do papel social e democrático}

Os meios de comunicação cumprem, historicamente, a função de informar e entreter a sociedade industrial. Com o avanço do sistema capitalista, o acesso aos meios de produção e distribuição se estabeleceu nas mãos dos proprietários de mídias, formando grandes conglomerados de comunicação que articulam todos os campos da agenda social. Sistematicamente, tais domínios sobre os meios de informação são criticados por intelectuais e pensadores que acusam as corporações de dirigismo político, econômico e cultural.

No último século, com o fortalecimento do poderio econômico dos 
conglomerados de mídias, a crítica anti-imperialista encontrou respaldo na sociedade informal. Em sua maioria, as críticas tecidas aos grandes empresários da comunicação se fundamentam em leis de livre concorrência e em ideais de consciência social. O que se verifica, de fato, é o resquício marxista de tais intelectuais, que fazem do apelo à democracia uma bandeira contra o poder e a influência das mídias no contemporâneo.

$\mathrm{Na}$ crítica à democracia, abriga-se o ressentimento dos intelectuais marxistas. Em outras palavras, essa crítica identifica o fracasso dos intelectuais, obrigados a exagerar, a explorar o espetacular, para tentarem legitimar-se enquanto intérpretes do social. O intelectual crítico só faz sentido se tudo estiver mal. A época atual assinala uma extraordinária crise de identidade dos intelectuais (LIPOVETSKY, 2004, p. 38).

O julgamento desses intelectuais sobre o papel social dos media tem como base a leitura de Marx sobre a alienação social decorrente da estratificação dos meios de produção. Com certa ressalva, o domínio dos meios de produção pode apresentar uma continuidade da luta de classes: considerando a sofisticação das técnicas e o volume de dinheiro que essa indústria movimenta, a crítica pode ser coerente, pertinente e propositiva. Posto de outra forma, a crítica é válida quando insiste na conscientização de que os processos comunicacionais são resultados da produção humana.

Em certas condições sociais, argumenta Marx, os poderes, produtos e processos humanos escapam ao controle dos sujeitos humanos e passam a assumir uma existência aparentemente autônoma. Apartados dessa forma de seus agentes, tais fenômenos começam então a exercer sobre eles um poder imperioso, de modo que homens e mulheres se submetem ao que, na verdade, são os produtos de sua própria atividade, como se estes fossem uma força estranha (EAGLETON, 1997, p. 71).

A esta crítica sobre o risco da alienação social nas atividades comunicacionais, devemos acrescentar o advento das novas tecnologias, e em especial, da Internet. A rede, como nova ferramenta de produção e distribuição de conteúdos, certamente mudou a prática dos meios de comunicação e define a contemporaneidade por sua 
facilidade de acesso, atualização e portabilidade. A adaptação dos conglomerados da comunicação resultou em portais e centros de informações no ambiente virtual. As novidades da tecnologia e o modelo participativo da rede transformaram o modelo político-econômico dos meios de comunicação; a indústria fonográfica, por exemplo, precisou lidar com a oferta gratuita de músicas e os serviços de troca e compartilhamento de arquivos via rede. A ampliação na capacidade de transferência de dados ameaça agora a indústria cinematográfica, que encontra seus produtos disseminados em servidores da rede. Por outro lado, a Internet oferece aos pequenos e médios produtores de mídias uma ferramenta poderosa de divulgação e distribuição dos seus trabalhos. Assim, o que se pode verificar de imediato é que a cultura digital reorganiza as hierarquias produtivas, promovendo uma abertura do mercado e um aumento do espectro midiático.

\begin{abstract}
A revolução superindustrial ratifica a falência do sistema industrial, que não é mais nem capitalista nem comunista, mas é, antes, a bancarrota da uniformização, da normalização e da centralização. Enterram-se as antigas ideologias rígidas e as velhas etiquetas de esquerda/direita, originárias do industrialismo. Rompem-se as instituições familiares e comunitárias. As velhas sociedades de massa se deslocam e se 'desmassificam' (MATTELART, 2004, p. 98).
\end{abstract}

Se por um lado reaparece, com a cultura digital, discussões sobre o papel social e democrático dos meios de comunicação, levando autores a retomar a postura clássica de Marx ou a teoria crítica de análise cultural da Escola de Frankfurt; por outro, o que verificamos de fato, conforme a proposição de Mattelart, é que a rede virtual agencia uma nova organização da estrutura produtiva dos meios de comunicação por oferecer, para a massa de usuários, a possibilidade de participação ativa no ambiente virtual.

A inclusão proporcionada pela Internet desvela uma heterogeneidade das relações sociais, característica que pode ser vivenciada na rede pelo agenciamento de links - a linkania ${ }^{\mathrm{i}}$ - que transporta o usuário em qualquer direção no ambiente virtual. A diversidade de informações dessa oferta supera a discussão ideológica de bases marxistas: mesmo que se possa refletir sobre o papel dos gatekeepers e editores de sites em relação ao controle das informações postadas, a própria técnica de produção é 
facilitada aos usuários, permitindo o acesso e o manuseio da ferramenta.

A linkania e o acesso facilitado aos meios de produção podem caracterizar a Internet como o meio de comunicação mais democrático entre as mídias. A liberdade de navegação no ambiente de rede rompe barreiras políticas, econômicas e culturais. $\mathrm{O}$ usuário "plugado" pode ser parte da produção de conteúdos e pode interagir com a comunidade conectada. Ao mesmo tempo, o usuário pode desbravar novos territórios, traçar caminhos de conhecimentos e emitir suas opiniões sobre os acontecimentos do mundo.

Porém, o caráter democrático de acesso e produção de conteúdos na Internet produz, paradoxalmente, o questionamento sobre as fontes de informação. Com o domínio da técnica, o usuário percebe a facilidade com que os conteúdos podem ser manipulados no ambiente em rede; vide o debate sobre a veracidade das pesquisas na Wikipedia ${ }^{i i}$. A proliferação de canais informativos (de proveniência duvidosa) e a alta velocidade de propagação na Internet completam a questão sobre o meio.

A percepção sobre essas práticas em rede, que geram dúvidas sobre a veracidade dos conteúdos postados e difundidos, nos direciona a uma equação que contrapõe a liberdade de imprensa, o monopólio midiático e a legitimação dos veículos de comunicação. A preocupação em apurar a acuidade das informações fazem os usuários procurar suas fontes de confiança que, em geral, representam os conglomerados de comunicação que se estabeleceram com emissoras de televisão, rádio e/ou jornais.

\section{Liberdade de imprensa, monopólio e legitimação dos veículos}

A questão que se estabelece entre a liberdade de imprensa, o monopólio midiático e a legitimação dos veículos é problematizada pelas práticas difusas dos processos comunicacionais no meio digital. Se por um lado, os canais que carecem de legitimação evocam a liberdade de imprensa para combater o monopólio midiático representado pelos grandes conglomerados de informação ("vazando" reportagens exclusivas, por exemplo); por outro, as empresas consagradas de comunicação 
empregam o mesmo direito para garantir suas autonomias contra o sistema político e econômico de seu país ou nação.

O debate é menos sobre as inflexões do direito constitucional - a discussão não entra no mérito do direito de informar ou do direito de ser informado -, é antes disso mais um reflexo da falta de fiscalização e regulação dos processos comunicacionais na contemporaneidade. A questão revela um problema de ordem social: a disputa por independência dos profissionais visa a transparência das atividades sociais e a liberdade de imprensa fortalece a classe frente os grandes conglomerados da indústria cultural; mas ao mesmo tempo, esses produtores independentes se aproveitam dos recursos de produção da indústria legitimada, replicando suas fontes de informação ou “embebendo" iii seus conteúdos midiáticos.

Certamente, é possível argumentar-se que a idéia de liberdade de imprensa tem sido e está sendo usada para defender, ao mesmo tempo, os interesses específicos dos jornalistas, como grupo profissional, e/ou os interesses de propriedade de proprietários de veículos de imprensa contra os grupos sócias subordinados, e que ela pode ser tão usada porque o conceito está desvinculado de considerações das realidades materiais de produção da imprensa (GARNHAM, 2004, p. 136).

A liberdade de imprensa, nota o autor, é usada nos Estados Unidos, na esteira dos direitos da Primeira Emenda da Constituição, "para reagir contra qualquer intervenção estatal para alterar a estrutura dos mercados da mídia e, em particular, os direitos de propriedade da mídia"; uma forma de assegurar o livre mercado de idéias e de proteger "o poder desigual sobre o fluxo de idéias que as estruturas de mercado existentes concedem a uma ínfima minoria dos economicamente poderosos". E continua:

Ao mesmo tempo que são usadas, como quando da idéia que se relaciona à liberdade criativa, para sustentar o status e a autonomia dos jornalistas e dos produtores da mídia como um grupo semiprofissional, às vezes contra as pretensões administrativas dos próprios proprietários, e se proteger do questionamento social de um conjunto específico de práticas culturais das quais os jornalistas são os guardiões místicos - o conceito de valores das notícias, por exemplo -, práticas que fornecem aos jornalistas poder sobre a representação simbólica de outros grupos sociais (GARNHAM, 2004, p. 136). 
A questão sobre a liberdade de imprensa e a liberdade de expressão se acentua na Internet com a proliferação de $b \log s$, comunidades e páginas de discussão que permitem uma ampliação dos debates da malha social. No outro lado dessa balança, as informações, muitas vezes, carecem de um fator legitimador que lhes dê relevância, visibilidade e repercussão. Nesse ponto, são as maiores redes de comunicação de massa que continuam a ocupar papel central no controle informacional para a sociedade, funcionando como editores de conteúdos; compartilhando informações, buscando atualizações factuais e verificando fontes.

Do que podemos notar que a legitimação dos veículos comunicacionais ocorre pela própria sociedade; através das escolhas de acesso, do valor de confiança agregado às fontes seguras e do julgamento ético das práticas do meio, os usuários fornecem os dados necessários para a regulação do setor. A preocupação com o fator legitimador do meio é válida pois a comunicação, como nota Wilson Gomes, é "um daqueles serviços que estão diretamente associados ao interesse público, como a ciência ou a educação, por exemplo, cujo controle particular está limitado àqueles aspectos que não afetam esta sua natureza" (GOMES, 2004, p. 181); ou seja, o direito à informação é um bem que está acima das agendas comerciais e dos interesses políticos dos proprietários de mídias. O autor encerra a questão:
A idéia de que a informação pode ser empregada conforme a conveniência dos particulares esbarra no fato de que não há sociedade democrática que não compreenda o efeito de controle da comunicação sobre o controle da sociedade. Assim, como não se pode admitir que as grandes corporações internacionais, o crime organizado, os departamentos financeiros etc., possam controlar os conteúdos da comunicação de massa, explorando-os de acordo com seu maior proveito e agrado, não se compreende porque grupos de interesse e partidos políticos, sem mais, o possa fazer (Ibid).

$\mathrm{O}$ autor defende que a sociedade democrática entende o papel desempenhado pelos media como veículos de controle informacional e que a mediação dos conteúdos faz parte da prática do meio. A percepção sobre a produção humana por trás dos processos comunicacionais responde o questionamento; não por menos porque podemos 
aplicar a mesma função seletiva de conteúdos entre os comunicadores subordinados, independentes ou marginais.

\section{Considerações finais}

O complexo da indústria da cultura, da informação e do entretenimento da comunicação de massas adquiriu importância no mundo dos negócios e assumiu posição central no modo de vida contemporâneo adaptando-se à dupla função de realizador e veiculador de materiais informativos e culturais e de vitrine para a exibição de materiais e serviços dos setores produtivos (GOMES, 2004, p. 300).

A análise das teorizações do campo comunicacional ajuda a compreender o contexto da crítica contra o modelo político-econômico e o monopólio midiático em ambiente de rede. Verifica-se a transposição do antigo modelo de negócios desse campo para a Internet e que os grandes conglomerados continuam a ocupar papel de destaque entre os usuários como fontes de informação e entretenimento para a sociedade. Porém, a crítica que se faz a essa continuidade da hegemonia dos media na cibercultura é insuficiente para explicar as práticas cotidianas do usuário: ora, a Internet oferece possibilidades de acesso e de produção - com caráter democrático e inclusivo -, facilitando a participação e a interação do usuário com a aldeia global.

O embate social não se esgota ao validar uma ou outra postura crítica frente os processos comunicacionais na Internet; o desenvolvimento das técnicas cibernéticas deverá trazer novos questionamentos sobre usos e as práticas em rede. O que podemos afirmar com propriedade é que a Internet teve um impacto sobre as estruturas dos media; se não é uma modificação completa dos negócios, certamente requereu uma adaptação dos meios de comunicação de massa para a nova ferramenta. 
A verdade das relações sociais e sobre como a cultura lhes dá forma não está certamente na superfície da vida cotidiana em uma sociedade como a nossa onde a ocultação é essencial para o bom funcionamento do sistema. Se o capitalismo sempre busca esconder o tanto de exploração e iniquidade necessárias para a manutenção do mundo sob a égide da forma mercadoria, a ofuscação só se acentua na nossa era dita pós-industrial, que encobre a luta de classes sob a saturação da mídia, e a fragmentação do sujeito sob os prazeres serializados do consumo (CEVASCO, 2008, p. 56).

Nesse sentido, a crítica endereçada aos modelos hegemônicos de comunicação na cultura digital revela, em primeiro lugar, uma disputa por espaços de visibilidade e legitimação. O caráter democrático facilita a criação de canais alternativos de comunicação, mas, paradoxalmente, depende das ferramentas e dos conteúdos desenvolvidas pelos grandes grupos de mídias. Um exemplo dessa dependência nos ambientes em rede ocorre no ato de incorporação de vídeos do YouTube: o usuário tem à disposição códigos de programação para "copiar e colar" na sua página, veiculando o vídeo selecionado diretamente para o seu canal pessoal; ao mesmo tempo o usuário agrega o player do servidor, divulgando sua marca e link de acesso.

A prática de incorporação atesta como os conteúdos veiculados na Internet assumem a função de mercadorias; indicadores de acesso podem apontar tendências culturais ou afetivas e transformar hits em produtos. "Se antes a cultura podia até ser vista como o espaço possível de contradição, hoje ela funciona de forma simbiótica com a economia: a produção de mercadorias serve a estilos de vida que são criações da cultura" (Ibid, p. 58). Sob essa perspectiva, as atividades contraculturais não conseguem evitar o modelo hegemônico e podem, mesmo que sem intenção, corroborar os processos comunicacionais que combatem.

Com isso, podemos concluir que a observação sobre as práticas sociais na Internet deve estar atenta aos movimentos de segmentação de gostos e valores de consumo. Afinal, a cibercultura se caracteriza pela apropriação da técnica e pelos usos e desvios no emprego das ferramentas pelos usuários (LEMOS, 2004); o que significa que a contracultura ou corre o risco de ser transmutada em mercadoria (indicando 
tendências, por exemplo) ou poderá ser desqualificada pelos meios legitimados. "A forma como os media tradicionais tratam o fenômeno do hacking reforça a infantilização desta cultura, como um modo de torná-la trivial e com isso neutralizá-la" (Ibid. p. 177).

A crescente fragmentação de produtos, conteúdos e mercadorias na Internet direcionados cada vez mais a nichos específicos da sociedade de consumo - ajuda a ocultar o próprio funcionamento dos processos comunicacionais no ambiente em rede; a saber, da regência do sistema capitalista em todos os aspectos da atividade social:

$\mathrm{Na}$ era da indústria cultural, o indivíduo deixa de decidir autonomamente; o conflito entre impulsos e consciência soluciona-se com a adesão acrítica aos valores impostos: aquilo a que outrora os filósofos chamavam vida, reduziu-se à esfera do privado e, posteriormente, à do consumo puro e simples, que não é mais do que um apêndice do processo material da produção, sem autonomia e essência próprias (WOLF, 2008, p. 86).

O que se propõe, então, é menos um ataque aos sistemas de produção ou aos debates de fundo ideológico sobre o campo comunicacional; é mais uma recuperação dos contextos históricos para compreender o funcionamento dos processos de comunicação na contemporaneidade e para conscientizar os usuários da cibercultura sobre os efeitos e apropriações da alienação na sociedade de consumo.

\section{Referências Bibliográficas}

CEVASCO, Maria Elisa. O sentido da crítica cultural. Dossiê Marxismo no Império. Revista Cult. São Paulo, ano $11, \mathrm{n}^{\circ} 122$, março/2008, p. 54-58.

DELEUZE, Gilles; PARNET, Claire. Diálogos. Tradução de Eloísa Araújo Ribeiro. São Paulo: Escuta, 1998.

DIMANTAS, Hernani. Linkania. Dossiê Rebeldia Agora. Revista Cult. São Paulo, ano 8, nº 95, setembro/2005, p. 56-58.

EAGLETON, Terry. Ideologia. Uma introdução. Tradução de Silvana Vieira e Luís Carlos Borges. São Paulo: Editora da Universidade Estadual Paulista - Boitempo, 1997.

GARNHAM, Nicholas. Bourdieu, o arbitrário cultural e a televisão. In: MARTINS, Francisco Menezes; SILVA, Juremir Machado da (Org.). A genealogia do virtual: comunicação, cultura e tecnologias do 
imaginário. Porto Alegre: Sulina, 2004, p.127-145.

GOMES, Wilson. Transformações da política na era da comunicação de massa. São Paulo: Paulus, 2004.

LEMOS, André. Apropriação, desvio e despesa na cibercultura. In: MARTINS, Francisco Menezes; SILVA, Juremir Machado da (Org.).. A genealogia do virtual: comunicação, cultura e tecnologias do imaginário. Porto Alegre: Sulina, 2004, p. 171-189.

LIPOVETSKY, Gilles. Sedução, publicidade e pós-modernidade. In: MARTINS, Francisco Menezes; SILVA, Juremir Machado da (Org.). A genealogia do virtual: comunicação, cultura e tecnologias do imaginário. Porto Alegre: Sulina, 2004, p. 33-42.

MATTELART, Armand. A era da informação: gênese de uma denominação descontrolada. In: MARTINS, Francisco Menezes; SILVA, Juremir Machado da (Org.). A genealogia do virtual: comunicação, cultura e tecnologias do imaginário. Porto Alegre: Sulina, 2004, p. 81-107.

WOLF, Mauro. Teorias das comunicações de massa. São Paulo: Martins Fontes, 2008.

Este artigo e todo o conteúdo da Estudos em Jornalismo e Mídia estão disponíveis em http://www.periodicos.ufsc.br/index.php/jornalismo/index

Estudos em Jornalismo e Mídia está sob a Licença Creative Commons 
i O termo "linkania" está definido no artigo de Hernani Dimantas para o Dossiê Rebeldia Agora da Revista Cult, $\mathrm{n}^{\circ}$ 95, setembro de 2005.

ii A Wikipedia é apenas o exemplo mais conhecido da prática colaborativa em rede. Outros casos exploram a função open source, em que os usuários podem editar a programação da ferramenta.

iii O termo se popularizou para designar a prática de incorporação de códigos html, geralmente em conteúdos de áudio e/ou vídeo. Tem origem no inglês "embed". 